\title{
STEROID DEPENDENT ULCERATED ERYTHEMA NODOSUM LEPROSUM 16 YEARS AFTER SUCCESSFUL TREATMENT OF LEPROSY
}

\author{
ZANNATUN NUR ${ }^{1}$, FAZLE RABBI MOHAMMED ${ }^{1}$, MONZURUL H CHOWDHURY ${ }^{1}$, MD ZIAUS SHAMS ${ }^{2}$, \\ MD.BILLAL ALAM ${ }^{3}, \mathrm{H}^{\text {A M NAZMUL AHASAN }}{ }^{4}$
}

\section{Introduction}

Leprosy could be best understood as two conjoined diseases. The first is a chronic mycobacterial infection that elicits an extraordinary range of cellular immune responses. The second is lepra reaction, whose course and sequelae often extend many years beyond the cure of the infection and may have severely debilitating physical, social and psychological consequences. ${ }^{1}$ Type-2 lepra reaction is also termed Erythema nodosum leprosum (ENL) regardless of the site of involvement, which is in turn a Coomb and Gell Type III hypersensitivity reaction. ${ }^{2}$ The paradox of ENL is that it can be a life-threatening disorder and requires control with immunosuppression which may itself pose life-threatening risks for patients Indian studies found its prevalence rate of almost 50\% in those with LL and $9 \%$ in BL cases and the mean time to presentation with ENL was 3.7 months after starting multi-drug therapy (MDT). ${ }^{3}$ Hitherto we report a severe and steroid dependent case of chronic ulcerated ENL, not only occurred sixteen years after successful treatment of lepromatous leprosy, but also had an unusual initial presentation of arthritis. To the best of our knowledge, ENL for such a prolonged period of 15 years was not reported earlier.

\section{Clinical synopsis}

A 36-year-old non-diabetic lady was admitted in the Department of Medicine, with multiple cutaneous ulcerations over the legs, hands, trunk and buttocks for one month. She had been diagnosed as a case of lepromatous leprosy 18 years back and had completed successfully a two years long multi drug treatment. Thereafter she led a completely healthy life for one year. It is the gradual swelling and pain over her left ankle joint, which incepted her misery. The pain was progressive and within one month the successive involvement of right ankle, bilateral knees, elbows and small joints of hands compelled her to consult nearby hospital. After intake of oral prednisolone for two months she had got complete relief. Unfortunately, she again developed polyarthritis four months later and had had a course of oral steroid and NSAIDs once again. Since then arthralgia became a part of her life which gets worse time to time. She found steroid as a savior at her worst times, which provoked her to self-administer steroid whenever she thought required.

One month before admission, she developed crops of painful erythematous papules over the upper limbs.The skin lesions appeared overnight and similar lesions involved whole body over a few days with a gradual evolution to nodules, pustules and ulcers along with fever, severe bodyache and fatigue.

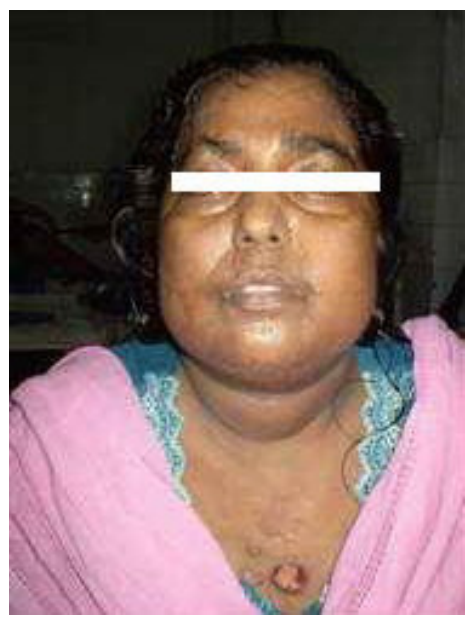

Fig.-1: Puffy face with deep ulcer over the chest.

1. Post-graduate Trainee, Department of Medicine, Dhaka Medical College \& Hospital.

2. Assistant Registrar, Medicine Unit - 3, Dhaka Medical College \&Hospital.

3. Associate Professor, Department of Medicine, Dhaka Medical College.

4. Professor, Department of Medicine, Dhaka Medical College.

Correspondence : Dr. Zannatun Nur, Department of Medicine, Dhaka Medical College \& Hospital. E-mail: zannatunnur58@gmail.com 
On admission she was found having features of Cushing syndrome with puffy face(figure 1), thin skin and abdominal striae. There was no lymphadenopathy or oral ulcer. Multiple ulcers of variable size and shape were present over the four limbs, trunk and buttocks. They had marginal erythema, ragged margins and exudative base (figure 2).The joints were mildly swollen and tender with evidence of active sinovitis. The ulnar, lateral popliteal and great auricular nerves were thickened and tender bilaterally. Deep tendon reflexes and sensations were preserved. Fixed flexion deformity of little finger of right hand was found indicating previous ulner nerve palsy.

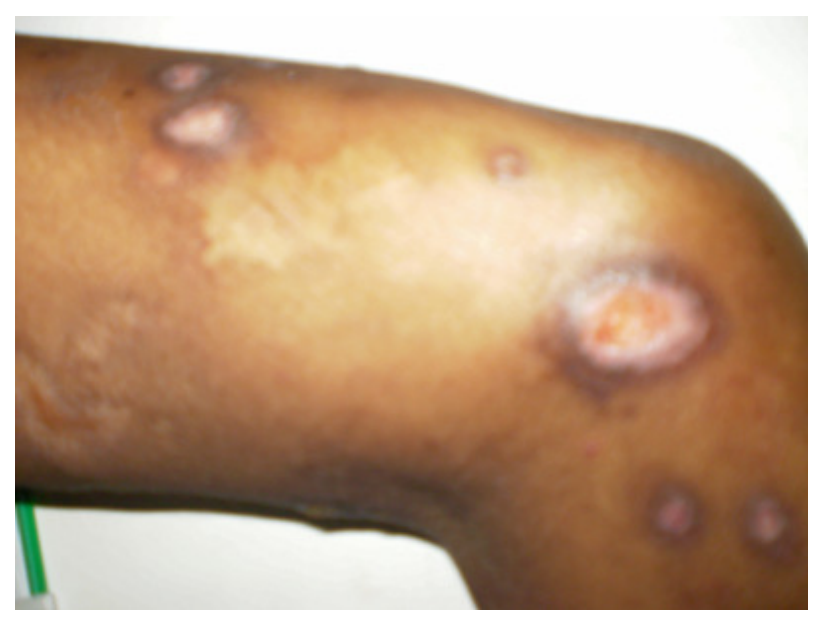

Fig.-2: Healing ulcers over the upper limb.

Complete hemogram revealed hemoglobin of $11 \mathrm{~g} / \mathrm{dl}$, total leukocyte count of $8,000 / \mu \mathrm{L}$ with neutrophilcount of $72 \%$. Erythrocyte sedimentation rate was $28 \mathrm{~mm}$ in the first hour. Renal function tests, urinalysis, chest X-ray, blood sugar, antinuclear antibody, rheumatoid factor, anti dsDNA, anti HCV antibody studies were within normal limit.

Slit-skin smear examination revealed a bacterial index (BI) of $3.3+$ with $4+$ from forehead and morphological index was zero (100\%granularacid-fastbacilli).Biopsy from the ulcer margin revealed an ulcerated epidermis and dermis lined by granulation tissue and infiltration with mixed inflammatory cells with predominance of neutuophil. A diagnosis of ENL with steroid induced Cushing syndrome was made. She was started on oral prednisolone $40 \mathrm{mg}$ daily as a single morning dose along with local wound care and antibiotics. After improvement of general condition, she was discharged after two weeks, with gradual tapering of dose of prednisolone.

Four weeks later she came at follow up with the complaints of low back pain and occasional new crops of tender nodules over upper limb and abdomen. Our next consideration was to prescribe thalidomide 100 daily, finding inadequate response and complications of steroid and she was not planning for child. In Bangladesh there is no designated centre for thalidomide. It is not easily available, and the cost is out of reach of general people. Being an apparently ostracized person, it was out of question for her to afford the drug. She was started on oral prednisolone $40 \mathrm{mg}$ for one week followed by methylprednisolone acetate $80 \mathrm{mg}$ intramuscularly 2 weekly for two months and clofazimine $300 \mathrm{mg}$ nightlly. Calcium and vitamin D supplements were also added. She is on regular follow up now.

\section{Discussion:}

Recurrent crops of tender, evanescent, erythematous nodules associated with fever and other constitutional symptoms characterize classic erythema nodosum leprosum (ENL). ${ }^{4}$ Less commonly, the lesions may be hemorrhagic, vesicular, erythema-multiforme-like, pustular, or ulcerated. ${ }^{5}$ Arthritis with type I and II lepra reaction is typically acute onset, symmetric or asymmetric, oligo- or poly-arthritis and may resemble rheumatoid arthritis (RA) or seronegative spondyloarthropathy. ${ }^{6}$ In our case, the symmetric polyarthritis could be misdiagnosed as RA and clinical consideration of ENL was difficult initially in the absence of cutaneous manifestations. Moreover, ulcer is an unusual presentation of leprosy. These may occur as a result of neuropathy, ENL or due to Lucio's phenomenon. ${ }^{7,8}$ Here, the ulcers were generalized and Lucio's phenomenon was also ruled out as it is very rare outside Caribbean region and histopathology did not show any bacilli in vessel wall or any thrombosis of dermal vessels. Finally, the $3.3+\mathrm{BI}$ in the slit skin smear and thickened nerves confirmed the diagnosis of ENL. But what induced the skin lesions to appear after a long period of 15 years, is a puzzle. The usual trigger sassociated with ENL reaction include surgical operations, pregnancy, parturition, lactation, menstruation, trauma, intercurrent illness, vaccination, physical or mental stress, and sometimes therapy.

The real challenge we faced during the management of the patient. ENL reactions are usually recurrent or chronic and predicting which clinical pattern an individual's disease will follow is not possible. ${ }^{3}$ The 1998 WHO Expert Committee on Leprosy report discussed the 
the management of type 1(reversal) reactions and ENL together advising that 'severe ENL can be treated with prednisolone, as for reversal reaction' (a 12-week course of prednisolone). ${ }^{9}$ This overlooks the chronic, recurrent nature of ENL. Treatment with clofazimine improves ENL, but it does not control severe ENL and takes 4 to 6 weeks to become active. ${ }^{10}$ Also the WHO Expert Committee recommended that the drug should not be maintained at this dose (300 $\mathrm{mg}$ daily) for more than a year. ${ }^{9}$ Thalidomide is now considered the drug of choice for ENL. ${ }^{10}$ It was approved by the FDA in the USA in 1998 'in the acute treatment of the cutaneous manifestations of moderate to severe ENL and as maintenance therapy for prevention and suppression of the cutaneous manifestations of ENL recurrences. ${ }^{11}$

Leprosy is the most ancient disease in the history of mankind and it is not going to disappear any time soon. Bangladesh has made appreciable progress in the control of leprosy by achieving the elimination goal 2 years ahead the target date set by the World Health Organization (WHO). ${ }^{12}$ It is said that, after 2005 we have entered a new, "post-elimination" era where leprosy is rare. But, during the "elimination" era, the only priority was achieving the elimination target by bringing down the prevalence rate at any price, without paying adequate attention to quality control and many essential activities like prevention of disability, management of complications. ${ }^{13}$ But killing the bacilli does not mean that the battle against leprosy has come to an end. Management of Lepra reactions, should be integrated into the general health services. Either thalidomide should be provided in the approved leprosy control centers under close supervision or a safe and cost-effective alternative to steroids or thalidomide should be developed. We require renewed commitment from all partners working towards the common goal of a world without leprosy and National Manual for Leprosy Control is to be revised.

\section{References:}

1. Scollard DM, Adams LB, Gillis TP, Krahenbuhl JL,Truman RW, Williams DL. The Continuing Challenges of Leprosy. Clinical Microbiology Reviews 2006;19(2):338-381

2. Pfalzgraff RE, Ramu G. Clinical leprosy. In: Hastings RC ed. Leprosy, 2nd edn. Churchill Livingstone, Edinburgh 1994, pp. $237-290$

3. Pocaterra L, Jain S, Reddy R, Muzaffarullah S, Torres O, Suneetha S et al. Clinical course of erythema nodosum leprosum: an 11-year cohort study in Hyderabad, India. Am J Trop Med Hyg, 2006; 74: $868-879$.

4. Meyerson MS. Erythema nodosum leprosum. Int J Dermatol 1996; 35: 389-392

5. Jacobson RR, Trautman JR. The diagnosis and treatment of leprosy. South Med J 1976 ; 69(8):979-85.

6. Cossermelli-Messina W, Festa Neto C, Cossermelli W Articular inflammatory manifestations in patients with different forms of leprosy. J Rheumatol. 1998; 25:111-9.

7. Britton WJ, Lockwood DN. Leprosy. Lancet 2004; 363(9416):1209-19.

8. Gelber RH. Leprosy (Hansens disease). In: Kasper DL, Braunwald E, Fauci AS, Longo DL, Jamison LJ eds. Harrisons Principles of Internal Medicine16th edn. New York: Mc Graw Hill, 2004; 1: 966-72.

9. Expert WHO. Committee on Leprosy. World Health Organ Tech Rep Ser., 1998; 874: 1-43.

10. Walker SL, Waters MFR, Lockwood DNJ. The role of thalidomide in the management of erythema nodosum leprosum. Lepr Rev 2007; 78: 197-215

11. www.fda.gov/cder/foi/appletter/1998/20785ltr.pdf. (Accessed 8th August 2007)

12. World Health Organization, Bangladesh. Communicable disease- Leprosy. URL:http://www.whoban.org/communicable_dis_leprosy.html. Accessed 21st January 2009.

13. Ji B.Comments on WHO/AFRO's "Post-Elimination" Strategy Paper: A New Bottle with Old Wine of the "Final Push". International Journal Of Leprosy 2005; 73(3): $216-18$ 